\title{
Hubungan antara Derajat Fungsi Motorik Kasar dan Status Gizi pada Anak Serebral Palsi Tipe Spastik
}

\author{
Ratih Eka Pujasari, Kusnandi Rusmil, Dadang Hudaya Somasetia \\ Departemen Ilmu Kesehatan Anak Fakultas Kedokteran Universitas Padjadjaran/RSUP Dr. Hasan Sadikin, Bandung
}

Latar belakang. Serebral palsi (CP) merupakan penyebab disabilitas kronik tersering pada anak. Anak CP mengalami pertumbuhan kurang baik, seiring dengan bertambah beratnya derajat fungsi motorik kasar. Tebal lipat kulit (TLK) dan lingkar lengan atas (LLA) merupakan parameter antropometri yang dapat digunakan untuk menilai status gizi anak CP tipe spastik.

Tujuan. Menganalisis hubungan derajat fungsi motorik kasar dengan status gizi pada anak CP tipe spastik

Metode. Penelitian dengan rancang potong lintang. Subjek adalah anak usia 1-18 tahun telah terdiagnosis CP tipe spastik, kontrol ke klinik neuropediatri, ilmu kedokteran fisik dan rehabilitasi (IKFR) RS.Hasan Sadikin Bandung dan klinik sekolah luar biasa Yayasan Pendidikan Anak Cacat (YPAC) Bandung, dipilih secara consecutive sampling pada Mei-Juni 2019. Dilakukan pemeriksaan derajat fungsi motorik kasar menggunakan gross motor function classification system (GMFCS), pengukuran LLA dan TLK triseps. Uji statistik menggunakan Uji chi-kuadrat, dengan nilai kemaknaan $\mathrm{p}<0,05$.

Hasil. Enam puluh anak CP tipe spastik mengikuti penelitian, terdiri dari 28 laki-laki dan 32 perempuan. Terdapat 28 anak $(46,7 \%)$ memiliki status gizi kurang dan 2 anak (3,3\%) memiliki status gizi lebih berdasarkan LLA. Terdapat 12 anak (20\%) memiliki status gizi kurang berdasarkan TLK triseps. Tidak terdapat hubungan antara derajat fungsi motorik kasar dan status gizi berdasarkan LLA $p=0,388$ dan TLK $p=0,605$. Terdapat hubungan topografi dengan status gizi berdasarkan LLA $p=0,016$. Kesimpulan. Tidak terdapat hubungan antara derajat fungsi motorik kasar dan status gizi. Sari Pediatri 2020;21(6):364-70

Kata kunci: serebral palsi, status gizi, fungsi motorik kasar, anak

\section{Relationship between Gross Motor Function and Nutritional Status in Children with Spastic Type Cerebral Palsy}

Ratih Eka Pujasari, Kusnandi Rusmil, Dadang Hudaya Somasetia

Background. Cerebral palsy (CP) is the most common cause of chronic disability in children. Children with CP have a higher risk of experiencing poor growth, along with the increasing degree of gross motor function. Skin folding thickness (TSF) and upper arm circumference (UAC) are anthropometric parameters that can be used to assess the nutritional status of spastic type CP children.

Objective. To analyze the relationship between gross motor function degree and nutritional status of children with spastic type CP. Methods. This is a cross-sectional study. Subjects were children aged 1-18 years diagnosed with spastic type CP, who came to neuropediatric and physical and rehabilitation outpatient clinics Hasan Sadikin Hospital and YPAC school for special needs children Bandung, selected by consecutive sampling in May-June 2019. We performed gross motor function degree examination by using the gross motor function classification system (GMFCS), upper arm circumference, and TSF measurements. Statistical tests were done using the chi-square test, with p value of $<0.05$ being significant.

Result. Sixty spastic type CP children participated in the study, consisting of 28 males and 32 females. Twenty-eight (46.7\%) children were undernourished and 2 (3.3\%) were over nourished according to UAC measurements. Twelve (20\%) patients were undernourished according to TSF measurements. There was no correlation between gross motor function degree and nutritional status based on UAC $(\mathrm{p}=0.388)$ and TSF $(\mathrm{p}=0.605)$. There was a topographic relationship with nutritional status based on UAC $(\mathrm{p}=0.016)$.

Conclusion. There is no relationship between the degree of gross motor function and nutritional status. Sari Pediatri 2020;21(6):364-70

Keywords: cerebral palsy, nutritional status, gross motor function, child

Alamat korespondensi: Ratih Eka Pujasari. Departemen Ilmu Kesehatan Anak Fakultas Kedokteran UNPAD Gedung Kenanga Lantai 3, Jl. Pasteur No.38, Bandung 40163. Email:Ratihep@gmail.com 
Ratih Eka Pujasari dkk: Hubungan antara derajat fungsi motorik kasar dan status gizi pada anak serebral palsi tipe spastik

S erebral palsi (CP) merupakan penyebab disabilitas kronis tersering pada anak dengan prevalensi 2-2,5 kasus per 1000 kelahiran hidup. ${ }^{1,2}$ Angka kejadian CP di negara berpenghasilan tinggi, yaitu 2,11 per 1000 kelahiran hidup dan di negara berpenghasilan menengah ke bawah dilaporkan lebih tinggi, dapat mencapai 10 per 1000 kelahiran hidup ${ }^{3,4}$ Serebral palsi tipe spastik merupakan tipe yang paling sering ditemukan, mencapai 70\% hingga 80\% dari keseluruhan kasus CP. ${ }^{5,6}$

Gangguan perkembangan motorik dan postur pada CP seringkali disertai dengan gangguan perkembangan sensoris, persepsi, kognisi, bahasa dan/ atau perilaku, epilepsi dan masalah muskuloskeletal sekunder serta masalah nutrisi. ${ }^{1,7,8}$ Gangguan motorik dan postur yang kronik menyebabkan anak CP mengalami penurunan fungsi dan tidak mampu melakukan aktivitas sehari-hari sehingga memerlukan bantuan orang lain dan menjadi beban bagi keluarga, terutama orang tua.. ${ }^{910}$ Anak CP dapat mengalami pertumbuhan yang kurang baik, seiring dengan bertambah beratnya derajat fungsi motorik kasar. ${ }^{11,12}$

Gangguan nutrisi pada anak CP dapat bermanifestasi sebagai gizi kurang maupun gizi lebih. ${ }^{11,13,14}$ Gangguan nutrisi dapat dipengaruhi oleh faktor nutrisi maupun non-nutrisi, termasuk gangguan motorik, masalah saluran cerna, riwayat pengobatan, gangguan endokrin, dan status sosioekonomi. ${ }^{11,12}$ Penelitian di Bosnia Herzegovina menunjukkan bahwa sebesar 26,5\% anak CP dengan disfungsi motorik kasar ringan mengalami gizi kurang dan anak CP dengan disfungsi motorik kasar berat sebesar 63\%, serta 10,9\% anak CP dengan disfungsi motorik kasar berat mengalami obesitas. ${ }^{11,15}$ Penelitian lain di Columbia menunjukkan bahwa stunting dan malnutrisi sering terjadi pada anak CP dan berhubungan langsung dengan derajat berat disfungsi motorik kasar. ${ }^{12}$ Penelitian yang dilakukan di Korea menunjukkan hasil yang berbeda, yaitu tidak terdapat korelasi bermakna antara fungsi motorik kasar dan status gizi, walaupun anak CP dengan disfungsi motorik kasar berat memiliki risiko tinggi mengalami malnutrisi. ${ }^{16}$ Karena hubungan antara derajat fungsi motorik kasar dan status gizi masih kotroversial, peneliti ingin meneliti mengenai hubungan antara derajat fungsi motorik kasar dan status gizi pada anak CP tipe spastik.

\section{Metode}

Bentuk penelitian ini adalah analitik observasional dengan rancangan potong lintang (cross sectional) pada anak usia 1-18 tahun yang telah terdiagnosis CP tipe spastik sebelumnya dan kontrol ke Klinik Neuropediatri, klinik Ilmu Kedokteran Fisik dan Rehabilitasi (IKFR) Rumah Sakit Hasan Sadikin (RSHS) Bandung dan Klinik Sekolah Luar Biasa (SLB) Yayasan Pendidikan Anak Cacat (YPAC), pada bulan Mei-Juni 2019. Pemilihan sampel dilakukan dengan cara consecutive sampling. Jumlah sampel didapatkan 60 subjek. Kriteria inklusi adalah anak usia 1-18 tahun yang telah terdiagnosis CP tipe spastik, kontrol ke Klinik Neuropediatri, IKFR RSHS Bandung dan SLB YPAC, memiliki status sosioekonomi keluarga menengah ke atas. Orang tua telah mengizinkan dan telah menandatangani persetujuan (informed consent) orang tua. Kriteria eksklusi adalah adanya riwayat penyakit kronis seperti tuberkulosis, diabetes mellitus, penyakit jantung bawaan dan keganasan yang telah diketahui sebelumnya, memiliki cacat bawaan orofasial, dan menggunakan gastrostomi atau selang nasogaster. Penelitian ini telah memperoleh kelayakan etik dari Komite Etik RSHS dengan nomor LB.02.01/X.6.5/152/2019.

Untuk mendapatkan subjek penelitian, setiap anak yang telah terdiagnosis CP tipe spastik, kontrol ke Klinik Neuropediatri dan IKFR RSHS Bandung dan SLB YPAC diberikan penjelasan kepada orang tua serta melakukan informed consent. Setelah orang tua mengisi data penelitian, subjek penelitian dilakukan pemeriksaan derajat fungsi motorik kasar menggunakan perangkat Gross motor function Classification System (GMFCS) dan dilakukan pengukuran lingkar lengan atas (LLA) pada pertengahan antara acromion dan olekranon menggunakan flexible tape measure merek Seca yang telah dikalibrasi dan pengukuran tebal lipat kulit (TLK) triseps yang dilakukan di daerah triseps, yaitu pertengahan antara acromion dan olekranon menggunakan caliper skinfold merek Lange. Pengukuran dilakukan dua kali, kemudian diambil nilai rerata. Status gizi ditentukan berdasarkan kriteria Frisancho yaitu gizi kurang: < peresentil 5, gizi baik: persentil 5-persentil 95, gizi lebih: $\geq$ persentil 95 .

Data yang terkumpul diolah dan dianalisis secara deskriptif dan analitik. Analisis deskriptif atau analisis univariabel menggambarkan karakteristik subjek penelitian dengan menyajikan ukuran statistik jumlah 
dan persentase untuk data kategori, yaitu data jenis kelamin, topografi, klasifikasi GMFCS, LLA dan TLK triseps. Analisis selanjutnya berupa analisis bivariabel.

Analisis bivariabel untuk menganalisis hubungan antar variabel digunakan uji statistik uji chi-kuadrat untuk menganalisis hubungan dua variabel data kategorik, yaitu hubungan derajat fungsi motorik kasar berdasarkan GMFCS, topografi dengan status gizi berdasarkan LLA dan TLK triseps, jika ada nilai ekspektasi sel $<5$ digunakan uji eksak Fisher. Untuk mengukur besarnya pengaruh dihitung rasio prevalensi dan interval kepercayaan 95\%. Kemaknaan hasil uji statistik ditentukan berdasarkan nilai $\mathrm{p}<0,05$. Analisis data dilakukan dengan menggunakan program SPSS for windows versi 20.0 pada derajat kepercayaan 95\% dengan nilai $\mathrm{p} \leq 0,05$.

\section{Hasil}

Selama penelitian diperoleh subjek 60 anak CP tipe spastik yang memenuhi kriteria penelitian. Subjek penelitian terbanyak berusia 60-131 bulan, yaitu 21 (35\%), 15 (25\%) anak berusia 24-59 bulan, $16(26,7 \%)$ berusia $131-216$ bulan dan $8(13,3 \%)$ berusia $<24$ bulan, berjenis kelamin perempuan $32(53,3 \%)$ dan $28(46,7 \%)$ anak berjenis kelamin laki-laki. Distribusi topografi terdiri dari diplegia, hemiplegia, dan quadriplegia. Jumlah terbanyak adalah quadriplegia, yaitu $29(48,3 \%)$, diplegia 27 (45\%) dan hemiplegia 4 (6,7\%) anak. Derajat fungsi motorik kasar berdasarkan GMFCS, dengan jumlah anak terbanyak level V 18 (30\%), level III 17 (28,3\%), dan level I 6 (10\%) anak. Status gizi anak berdasarkan

\begin{tabular}{lc} 
Tabel 1. Karakteristik subjek penelitian berdasarkan usia dan jenis kelamin $(\mathrm{n}=60)$ \\
\hline Karakteristik & $\mathrm{n}(\%)$ \\
\hline Usia (bulan) & $8(13,3)$ \\
$<24$ & $15(25,0)$ \\
$24-59$ & $21(35,0)$ \\
$60-131$ & $16(26,7)$ \\
$132-216$ & \\
Jenis kelamin & $28(46,7)$ \\
Laki-laki & $32(53,3)$ \\
Perempuan & \\
Topografi & - \\
Monoplegi & $27(45,0)$ \\
Diplegi & - \\
Triplegi & $4(6,7)$ \\
Hemiplegi & $29(48,3)$ \\
Quadripegi & \\
Derajat fungsi motorik berdasarkanGMFCS & $6(10,0)$ \\
Level I & $7(11,7)$ \\
Level II & $17(28,3)$ \\
Level III & $12(20,0)$ \\
Level IV & $18(30,0)$ \\
Level V & \\
Lingkar lengan atas & $28(20)$ \\
Gizi kurang & $30(50)$ \\
Gizi baik & $2(3,3)$ \\
Gizi lebih & \\
Tebal lipatan kulit & $12(20,0)$ \\
Gizi kurang & $48(80,0)$ \\
Gizi baik & - \\
Gizi lebih &
\end{tabular}


LLA menunjukkan 30 (50\%) gizi baik, 28 (46,7\%) gizi kurang, dan $2(3,3 \%)$ gizi lebih. Status gizi anak berdasarkan TLK triseps menunjukkan mayoritas subjek penelitian memiliki status gizi baik, yaitu 48 (80\%). Sementara $12(20 \%)$ memiliki status gizi kurang dan tidak ada yang memiliki status gizi lebih (Tabel 1).

Hubungan antara derajat fungsi motorik kasar, topografi dan status gizi berdasarkan LLA tertera pada Tabel 2. Diperoleh hasil bahwa tidak terdapat hubungan bermakna antara derajat fungsi motorik kasar dengan status gizi berdasarkan LLA ( $\mathrm{p}=0,388$;
RP 0,42). Berdasarkan topografi, anak CP tipe spastik diplegi yang memiliki gizi kurang sebesar 17 (63\%). Uji statistik menunjukkan hubungan bermakna antara topografi dengan status gizi berdasarkan LLA dengan nilai ( $\mathrm{p}=0,016 ; \mathrm{RP}-0,2)$. Hubungan antara derajat fungsi motorik kasar, topografi, dan status gizi berdasarkan TLK triseps tertera pada Tabel 3. Diperoleh hasil secara uji statistik menunjukkan tidak terdapat hubungan bermakna antara derajat fungsi motorik kasar, topografi dan status gizi berdasarkan TLK triseps $(\mathrm{p}=0,605 ; \mathrm{RP}-0,14 ; \mathrm{p}=0,579 ; \mathrm{RP} 0,12)$.

Tabel 2. Hubungan antara derajat fungsi motorik kasar, topografi dan status gizi berdasarkan LLA

\begin{tabular}{lccccc}
\hline \multirow{2}{*}{ Variabel } & \multicolumn{3}{c}{ Status gizi } & \multirow{2}{*}{ Nilai p } & \multirow{2}{*}{ RP (95\% CI) } \\
\cline { 2 - 3 } & Kurang & Baik & Lebih & & \\
\hline Topografii & & & & & \\
Monoplegi & $0(0)$ & $0(0)$ & $0(0)$ & 0,016 & $0,42(0,043-0,281)$ \\
Diplegi & $17(63)$ & $10(37)$ & $0(0)$ & & \\
Triplegi & $0(0)$ & $0(0)$ & $0(0)$ & & \\
Hemiplegi & $0(0)$ & $3(75)$ & $1(25)$ & & \\
Quadripegi & $11(37,9)$ & $17(58,6)$ & $1(3,4)$ & & \\
Derajat fungsi motorik & & & & \multirow{2}{*}{0,388} & $-0,2(-1,295-0,201)$ \\
berdasarkan GMFCS & & & & \\
Level I & $2(33,3)$ & $3(50)$ & $1(16,7)$ & & \\
Level II & $3(42,9)$ & $4(57,1)$ & $0(0)$ & & \\
Level III & $11(64,7)$ & $6(35,3)$ & $0(0)$ & & \\
Level IV & $5(41,7)$ & $6(50)$ & $1(8,3)$ & & \\
Level V & $7(38,9)$ & $11(61,1)$ & $0(0)$ & & \\
& & & &
\end{tabular}

Keterangan : chi square test*

Tabel 3. Hubungan antara derajat fungsi motorik, jenis kelamin, usia dengan status gizi berdasarkan TLK

\begin{tabular}{lccccc}
\hline Variabel & \multicolumn{3}{c}{ Status gizi } & Nilai p* & RP (95\% CI) \\
\cline { 2 - 3 } & Kurang & Normal & Lebih & & \\
\hline Topografi & & & & & \\
$\quad$ Monoplegi & $0(0)$ & $0(0)$ & $0(0)$ & 0,579 & $0,12(-0,057-0,124)$ \\
Diplegi & $6(22,2)$ & $21(77,8)$ & $0(0)$ & & \\
Triplegi & $0(0)$ & $0(0)$ & $0(0)$ & & \\
Hemiplegi & $0(0)$ & $4(100)$ & $0(0)$ & & \\
$\quad$ Quadripegi & $6(20,7)$ & $23(79,3)$ & $0(0)$ & & \\
Derajat fungsi otoric & & & & & \\
berdasarkanGMFCS & & & & & \\
Level I & $0(0)$ & $6(100)$ & $0(0)$ & 0,605 & $-0,14(-0,14-0,058)$ \\
Level II & $1(14,3)$ & $6(85,7)$ & $0(0)$ & & \\
Level III & $5(29,4)$ & $12(70,6)$ & $0(0)$ & & \\
Level IV & $2(16,7)$ & $10(83,3)$ & $0(0)$ & & \\
Level V & $4(22,2)$ & $14(77,8)$ & $0(0$ & & \\
\hline
\end{tabular}

Keterangan : chi square test* 
Ratih Eka Pujasari dkk: Hubungan antara derajat fungsi motorik kasar dan status gizi pada anak serebral palsi tipe spastik

\section{Pembahasan}

Serebral palsi (CP) merupakan kelompok gangguan perkembangan motorik dan postur yang bersifat permanen dan non-progresif. Hal tersebut menyebabkan keterbatasan aktivitas akibat dari kerusakan otak yang terjadi saat otak belum mencapai maturasi. ${ }^{1,7,8}$ Pola pertumbuhan pada anak CP tentunya berbeda dengan anak pada populasi pada umumnya. Pertumbuhan anak CP umumnya kurang baik seiring dengan bertambahnya derajat berat fungsi motorik kasar. ${ }^{11,12}$ Anak CP memerlukan pengukuran antropometri secara berkala untuk memantau pertumbuhan dan melakukan intervensi dini bila diperlukan. ${ }^{17}$

Penilaian status gizi anak CP dengan metode standar, seperti pengukuran berat badan (BB), tinggi badan (TB), dan indeks massa tubuh (IMT) cukup sulit. Hal tersebut dikarenakan adanya kontraktur sendi, atrofi otot, dan gangguan gerakan serta gangguan tonus otot maupun ketidakmampuan berdirisehingga diperlukan metode khusus agar dapat menilai pertumbuhan dengan benar. ${ }^{13,15}$ Metode yang dapat dilakukan untuk menilai status gizi anak CP adalah antropometri TLK dan LLA. ${ }^{15}$ Tebal lipat kulit merupakan parameter antropometri yang dapat digunakan untuk menilai status gizi dan adipositi. Pengukuran tebal lipat kulit merupakan instrumen penting untuk menilai status gizi pada pasien CP tipe spastik quadriplegia. ${ }^{18}$

Kami mendapatkan 30 (50\%) anak memiliki status gizi baik, $28(46,7 \%)$ gizi kurang, dan $2(3,3 \%)$ gizi lebih berdasarkan pengukuran LLA. Sementara status gizi anak berdasarkan TLK triseps menunjukkan $48(80 \%)$ anak memiliki gizi baik, 12 (20\%) anak memiliki gizi kurang, dan tidak ada yang memiliki status gizi lebih. Hasil tersebut tidak jauh berbeda dengan penelitian sebelumnya di Brazil. Penelitian tersebut melaporkan bahwa berdasarkan parameter LLA, 66,6\%, 1,85\%, dan 51,8\% subjek penelitian memiliki nilai berturut-turut antara persentil 5-persentil 95, > persentil 95, dan < persentil 5 . Parameter TLK triseps 66,7\% memiliki nilai triseps antara persentil 5-persentil 95 dan 29,63\% memiliki nilai < persentil $5 .{ }^{18}$ Hasil tersebut kemungkinan dikarenakan adanya mobilitas dan aktivitas fisik yang terbatas pada anak CP tipe spatik. Oleh sebab itu, stimulus untuk pembentukan massa otot berkurang. Anak CP tipe spastik cenderung mengalami penurunan massa otot dan peningkatan massa lemak dibandingkan dengan anak sehat. ${ }^{18}$

Pada penelitian kami, berdasarkan LLA derajat fungsi motorik kasar level I, II, III, IV, dan V yang memiliki status gizi kurang masing-masing sebesar $33,3 \%, 42,9 \%, 64,7 \%, 41,7 \%$, dan 38,9\%. Sementara berdasarkan TLK triseps, subjek dengan derajat fungsi motorik kasar level I dan IV yang memiliki gizi lebih $16,7 \%$ dan $8,3 \%$, sedangkan level II, III, dan V memiliki status gizi kurang 14\%, 29,4\%, 16,7\%, dan 22,2\%. Hasil tersebut berbeda dengan penelitian sebelumnya di Bosnia Herzegovina. Penelitian tersebut melaporkan bahwa anak CP dengan disfungsi motorik kasar ringan mengalami gizi kurang 26,5\% dan dengan disfungsi motorik kasar berat $63 \%$. Selanjutnya, anak CP dengan disfungsi motorik kasar ringan dan berat mengalami gizi lebih $11,8 \%$ dan $10,9 \%$. Pada penelitian di Columbia dilaporkan bahwa malnutrisi sering terjadi pada anak CP dan berhubungan dengan beratnya derajat fungsi motorik kasar. ${ }^{11,12,19}$ Perbedaan tersebut dikarenakaninstrumen, kriteria inklusi, dan eksklusi yang digunakan berbeda.

Pada penelitian kami, tidak didapatkan hubungan bermakna antara derajat fungsi motorik kasar dengan status gizi berdasarkan LLA dan TLK triseps. Pada anak CP, gangguan nutrisi dapat dipengaruhi oleh faktor nutrisi dan non nutrisi. Faktor nutrisi terdiri dari asupan nutrisi yang tidak adekuat. Hal tersebut diakibatkan oleh masalah pemberian makan, peningkatan kehilangan kalori, dan peningkatan penggunaan kalori. Faktor non nutrisi terdiri dari usia, genetik, faktor fisik yang berkaitan dengan kelainan neurologis, dan faktor endokrin. Faktor yang paling bermakna memengaruhi status gizi adalah asupan nutrisi yang tidak adekuat. Hal tersebut dapat disebabkan karena disfungsi oromotor, kesulitan menelan, kesulitan positioning, durasi makan yang lama dan perlunya bantuan saat makan. ${ }^{19}$ Gastroesophageal reflux juga menyebabkan anak $\mathrm{CP}$ mengalami kehilangan kalori yang bermakna. Gastroesophageal reflux akibat gangguan motilitas usus berhubungan dengan interaksi usus dan susunan saraf pusat yang terganggu, peningkatan tekanan intraabdomen yang terjadi secara sekunder akibat dari konstipasi kronik. Pertumbuhan anak CP dipengaruhi secara langsung oleh faktor neurotrop yang berhubungan dengan penyakit yang mendasari dan secara tidak langsung dipengaruhi oleh aktifitas fisik yang terbatas. ${ }^{20}$

Variasi pertumbuhan pada anak CP kemungkinan berhubungan dengan perubahan hormon pertumbuhan 
atau growth hormone $(\mathrm{GH})$ dan aksis hipotalamus pituitari. Hipotalamus berperan penting dalam mengatur rasa lapar, nafsu makan,dan homeostasis energi yang selanjutnya dapat memengaruhi pertumbuhan dan status gizi. ${ }^{20}$ Hormon pertumbuhan merupakan hormon yang berperan penting untuk mencapai pertumbuhan optimal. Anak CP memiliki risiko mengalami defisiensi $\mathrm{GH}$. Hal ini kemungkinan terjadi melalui beberapa mekanisme, yaitu abnormalitas antomi aksis hipotalamus-pituitari, perubahan psikososial, dan kerusakan otak yang berat memengaruhi sejumlah jalur neurotransmiter yang mengontrol GH. Level GMFCS dan beratnya spastisitas memiliki efek negatif terhadap sekresi GH. ${ }^{19}$ Faktor lingkungan seperti kepatuhan jadwal makan dan terapi medis yang dijalani juga memengaruhi pertumbuhan anak CP. Adanya keterbatasan sumber daya untuk memenuhi kebutuhan nutrisi, keterbatasan waktu, dan fasilitas untuk menyediakan makanan serta kurangnya kesadaran orang tua atau pengasuh mengenai pentingnya nutrisi menyebabkan timbulnya masalah pemberian makan pada anak CP yang selanjutnya akan memengaruhi pertumbuhan anak CP. ${ }^{19}$

Serebral palsi tipe spastik quadriplegi merupakan tipe CP yang paling sering mengalami gangguan oromotor sehingga memiliki risiko lebih tinggi mengalami gizi kurang. ${ }^{21}$ Penelitian Stalling $\mathrm{dkk}^{21}$ melaporkan bahwa anak CP tipe spastik diplegi dan hemiplegi tetap memiliki risiko mengalami malnutrisi. Pada penelitian kami, anak CP tipe spastik diplegia mengalami gizi kurang sebesar $63 \%$. Untuk mencapai proses pemberian makan yang efektif diperlukan kontrol postural yang baik. Anak CP memiliki kontrol postural yang buruk karena kontrol kepala dan tulang belakang yang lemah dan ketidakmampuan menjaga keseimbangan posisi badan. Kontrol postural yang buruk, terutama ditemukan pada CP tipe spastik quadriplegi yang menyebabkan asupan nutrisi tidak adekuat. $^{22}$

Pada suatu penelitian potong lintang yang menilai pertumbuhan pada anak CP dan dibedakan berdasarkan usia menunjukkan bahwa risiko gangguan pertumbuhan semakin besar seiring dengan bertambahnya usia. ${ }^{19}$ Penelitian lain yang dilakukan pada anak CP derajat berat juga menunjukkan korelasi negatif antara perlambatan pertumbuhan dan usia. ${ }^{23} \mathrm{Pe}-$ nelitian lain oleh Sjakti $\mathrm{dkk}^{22}$ melaporkan bahwa anak $\mathrm{CP}$ usia kurang dari 6 tahun mengalami perlambatan pertumbuhan sedikit lebih berat dibandingkan anak yang lebih tua. Hal ini kemungkinan dikarenakan peningkatan massa lemak tubuh dan perbaikan fungsi oromotor. Hasil tersebut tidak berbeda dengan penelitian di Korea yang melaporkan bahwa tidak terdapat korelasi bermakna antara fungsi motorik kasar dan status gizi, walaupun anak CP dengan disfungsi motorik kasar berat memiliki risiko tinggi mengalami malnutrisi. ${ }^{16}$ Hasil tersebut juga kemungkinan dipengaruhi oleh proses adipositas fisiologis yang terjadi pada rentang usia 5 sampai 6 tahun. ${ }^{13}$ Pada penelitian ini secara statistik tidak didapatkan hubungan fungsi motorik kasar dengan status gizi. ${ }^{16}$ Keterbatasan penelitian kami adalah peneliti tidak meneliti faktor yang memengaruhi status gizi, seperti asupan kalori, adanya disfungsi oromotor, gastroesofageal reflux, dan juga subjek penelitian yang kurang banyak.

\section{Kesimpulan}

Pada penelitian ini tidak didapatkan hubungan antara derajat fungsi motorik kasar dan status gizi pada anak CP tipe spastik.

\section{Daftar pustaka}

1. Canavese F, Deslandes J, penyunting. Orthopedic management of children with cerebral palsy. Italy: Nova Science Publisher, Inc; 2015.

2. Gunawan PI, Prasetyo RV, Irmawati M, Setoningrum RA, Saharso D, Prasetyo E. Risk factor of mortality in Indonesia children with cerebral palsy. J Med Invest 2018;65:18-21.

3. Tonmukayakul U, Bourke-Taylor H, Imms C, Reddihough D, Cox L, dkkl. Systemic review of the economic impact of cerebral palsy. J Res Dev Dis 2018;80:93-101.

4. Donald KA, Samia P, Kakooza-Mwesige A, Bearden D. Pediatric cerebral palsy in africa: A systematic review. Semin Pediatr Neurol 2014;21:30-5.

5. Ozkan Y. Child's quality of life and mother's burden in spastic cerebral plasy: A topographical classification perspective. J Int Med Res 2018:1-7.

6. McIntyre S MC, Walker K, Novak I. Cerebral palsy- don't delay. Dev disabil Res Rev 2011;17:114-15.

7. Graham HK, Rosenbaum P, Paneth N, Dan B, Lin JP, Damiano DL, dkk. Cerebral palsy. Nat Rev Dis Primers 2016;2:1-7.

8. Nelly RA. Keterlambatan motorik atau palsi serebral? IDAI Jaya. Jakarta: UKK Neurologi IDAI; 2010.h. 101-8. 
Ratih Eka Pujasari dkk: Hubungan antara derajat fungsi motorik kasar dan status gizi pada anak serebral palsi tipe spastik

9. Puspitari, Rusmil K, Gurnida D. The relationship between gross motor function and quality of life among children with cerebral palsy. DCIDJ 2013;24:58.

10. Park EY, Nam SJ. Time burden of caring and depression among parents of individuals with cerebral palsy. J Disabil Rehabil 2018:41:1508-13.

11. Melunovic M, Hadzagic-Catibusic F, Bilalovic V, Rahmanovic S, Dizdar S. Anthropometric parameters of nutritional status in children with cerebral palsy. Mater Sociomed 2017;29:68-72.

12. Herrera-Anaya E, Angarita-Fonseca A, Herrera-Galindo VM, Martinez-Marin RDP, Rodriguez-Bayona V. Association between gross motor function and nutritional status in children with cerebral palsy: A cross sectional study from columbia. Dev Med \& Child Neurol 2016;58:936-41.

13. Garcia Iniguez JA, Vasquez-Garibay EM, Garcia Contreras A, Romero-Velarde E, Troyo Sanroman R. Assessment of anthropometric indicators in children with cerebral palsy according to the type of motor dysfunction and reference standard. Nutr Hosp 2017;34:315-22.

14. Delalić A. Body mass index in cerebral palsy patients with various motor severities. Paediatrics Today 2014;10:95-103.

15. Maternal and Child Health Bureau. The CDC growth charts for children with special health care needs 2009. Diakses pada 10 Maret 2020. Didapat dari: https://www.cdc.gov/growthcharts/ clinical_charts.htm.
16. Im Yi T, Huh Seok W, Kyung Ku H, Seok Seo I, Won Shim J, Ean Lee G, dkk. Nutritional status of children with cerebral palsy. J korean Acad Rehab Med 2011;35:42-7.

17. CDC. National health and nutrition examination survey. NCFHS (NCHS) : US Department of Health and Human Services, Centers for Disease Control and Prevention; 2005.

18. Caselli TB, Lomaji EA, Montenegro MAS, Bellomo-Brandao MA. Assesment of nutritional status of children and adolescent with spastic quadriplegic cerebral plasy. Arq Gastroenterol 2017;54:204.

19. Anggarwal S, Chadha R, Pathak R. Nutritional status and growth in children with cerebral palsy: A review. Int J Med Sci and Public Health 2015;11:740.

20. Rempel $\mathrm{G}$. The importance of good nutrition in children with cerebral palsy. Phys Med Rehabil Clin N Am. 2015;26:3956.

21. Stallings VA, Charney EB, Davies JC, Cronk CE. Nutritional status and growth of children with diplegic or hemiplegic cerebral palsy. Dev Med Child Neurol 1993;35:997-1006.

22. Sjakti HA, Syarif D, Wahyuni LK, Chair I. Feeding difficulties in children with cerebral plasy. Pediatr Indones 2008;48:2249.

23. Stevenson RD, Cater LV, Blackman JA. Clinical correlates of linier growth in children with cerebral palsy. Dev Med Child Neurol 1994;36:135-42. 